\title{
Trend of mosquito (Diptera: Culicidae) monthly distribution in Sanandaj County of Iran
}

\author{
BAHAEDIN SALAVATI ${ }^{1}$, AMIR HOSSEIN ZAHIRNIA ${ }^{1}$, HASSAN NASIRIAN ${ }^{2, \bullet}$, \\ SHAHYAD AZARI-HAMIDIAN ${ }^{3}$ \\ ${ }^{1}$ Department of Medical Entomology, School of Medicine, Hamadan University of Medical Sciences. Hamadan, Iran. "email: hanasirian@yahoo.com \\ ${ }^{2}$ Department of Medical Entomology and Vector Control, School of Public Health, Tehran University of Medical Sciences. Tehran, Iran \\ ${ }^{3}$ Department of Health Education and Health Services, Research Center of Health and Environment, School of Health, Guilan University of Medical \\ Sciences. Rasht, Iran
}

Manuscript received: 3 May 2021. Revision accepted: 2 September 2021

\begin{abstract}
Salavati B, Zahirnia AH, Nasirian H, Hamidian SA. 2021. Trend of mosquito (Diptera: Culicidae) monthly distribution in Sanandaj County of Iran. Biodiversitas 22: 4705-4715. Mosquitoes are the most significant arthropods of medical importance due to their burden of transmitting pathogens and parasites. The present study was designed to investigate the distribution of mosquitos (Diptera: Culicidae) in Sanandaj County in 2018. Sanandaj County was divided into four areas in rural and urban areas, including north, south, east, and west. Four rural and urban areas were randomly selected from four geographical directions. A sampling of larval and adult mosquitoes was performed using standard methods. The dipping technique was used to collect the mosquito larvae. A sampling of adult mosquitoes was performed during feeding on humans and animal baits and resting in the natural indoors, outdoors, and artificial areas. Light traps were also used to collect adult mosquitoes. The larval and adult specimens were identified using the morphologybased key. In total, nine mosquito species, including Anopheles maculipennis s.l., Anopheles superpictus s.l., Culiseta longiareolata, Culiseta subochrea, Culex hortensis, Culex mimeticus, Culex modestus, Culex pipiens, and Culex theileri were inhabited in Sanandaj County. The larval and adult mosquito species trend remains constant for at least 6 months of a year, from May to October. One-way ANOVA didn't reveal a significant difference between mosquito breeding places' habitats and water types, mosquito localities and life stages, monthly mosquito distribution, and adult mosquito resting places. The frequency trends of larval and adult mosquito species remain constant at least for 6 months of a year. It needs to be ready for timely mosquito control measures.
\end{abstract}

Keywords: Frequency trend, larval habitats, monthly mosquito distribution, mosquito breeding places

\section{INTRODUCTION}

Mosquitoes (Diptera: Culicidae) are the most significant arthropods of medical importance due to their burden of transmitting pathogens and parasites such as encephalitis, filariasis, and malaria to humans. The family of Culicidae, depending on the generic classification of the tribe Aedini comprises 41 or 113 genera and 3563 species (Benelli and Duggan 2018; Azari-Hamidian et al. 2019; Suesdek 2019). The role of several species of mosquitoes in the bites and pruritus of humans, along with the transmission of pathogens, has doubled the medical importance of this family. Furthermore, the involvement of these vectors in the transmission of some pathogens among domesticated and wild birds and animals has put this family at the forefront of important medical and veterinary insects (Marm Kilpatrick et al. 2006).

Sanandaj is located in a mountainous area with a humid continental climate typified by four distinct seasons and large seasonal temperature differences with warm to hot (and often humid) summers and cold winters. It is the capital of Kurdistan Province in Iran and has valuable natural characteristics of cultural heritage, history and handicrafts, and abundant tourist attractions (Kakeh-Khani et al. 2020). Because mosquitoes are considered threats to human health along with long-lasting nuisance and itching of their bite positions, so the occurrence of mosquito distribution should be examined. It is a tourist destination despite the mosquito-borne diseases and human mosquito long-lasting nuisance (Lanciotti et al. 1999; Nasirian et al. 2014a; Nasirian et al. 2014b; Savage et al. 2007) that can prevent people activities and threaten the tourism industry. One individual serologically positive case of dengue fever who had not traveled abroad was recorded from Kurdistan Province. Rift Valley fever virus was detected recently by ELISA and indirect IFA in cattle and sheep in Kurdistan Province. Tularemia, caused by the bacterium Francisella tularensis, also occurs in rodents (Calomyscus, Meriones, Microtus, Dryomys nitedula, and Mus macedonicus) in Kurdistan Province (Mostafavi et al. 2017; Azari-Hamidian et al. 2019).

Previously Kazemi et al. (2010) and Banafshi et al. (2013) studied the fauna and frequency of mosquito larvae in Kurdistan Province (Kazemi et al. 2010; Banafshi et al. 2013). Due to climate and mosquito life stages change during different seasons and years, it seems necessary to study the mosquito distribution during intermittent periods. It also needs to be ready for timely control measures. Therefore, it needs to research to obtain further epidemiological aspects about diseases caused by the mosquito in the Sanandaj region. Given that there are many aquatic habitats in Sanandaj that can be a suitable place for 
the growth of Culicidae thus, the present study is designed to investigate the distribution of mosquitos in different parts of Sanandaj County in 2018.

\section{MATERIALS AND METHODS}

\section{Ethical approval}

The study was approved by the Ethics Committee of the Research Deputy of Hamadan University of Medical Sciences, Iran with approval number: IR.UMSHA.REC.1397.341.

\section{Area of study}

Kurdistan Province is located in the west of Iran with a land area of $29137 \mathrm{~km}^{2}$. Sanandaj, the capital of Kurdistan Province in Iran, is located at an altitude of 1538 meters in the south of Kurdistan Province. The area has a humid continental climate, and its coordinates are $35^{\circ} 18^{\prime} 52^{\prime \prime} \mathrm{N}$ $46^{\circ} 59^{\prime} 32^{\prime \prime} \mathrm{E}$. The average annual precipitation is about $490.6 \mathrm{~mm}$.

\section{Selection sites of the study area}

Based on similar studies (Kazemi et al. 2010; Banafshi et al. 2013) and available facilities, Sanandaj County was divided into four areas, including north, south, east, and west. Four urban areas of Sanandaj from four municipal areas were randomly selected. Based on the Sanandaj map, which was taken from the county governor's site, the selected sites were Doveyseh (municipal area two) from the north, Gerizeh (municipal area four) from the south, Abidar (municipal area one) from the east, and Baba-Riz (municipal area three) from the west. Four rural areas were also randomly selected from geographical directions. The villages were Salavat-Abad from North, Turivar from South, Kani-Moshkan from East, and Naran from West. In each municipal area, two stationary and variable stations were selected. In each rural area, four stationary (two humans and two animal stations) and variable (two humans and two animal stations) stations were selected. Adult and larval sampling took place every 15 days for 6 months, from May to October 2018. The temperature of the environment and water of mosquito breeding places and environment humidity were also measured during the study period.

\section{Sampling of mosquitoes}

A sampling of adult mosquitoes was performed at each station during feeding on humans and animal baits (cattle, goats, and/or sheep depending on availability in rural areas) and also resting in the natural indoors (homes, stables, toilets, and warehouses), outdoors (all kinds of shrubs, grasses, trunks of trees, and inside rock slits), and artificial areas such as water wells for 30 minutes. Light traps were also used to collect adult mosquitoes at each station. Each adult specimen was killed by placing it inside a glass jar containing potassium cyanide. In the laboratory, the adult specimens were identified under a stereomicroscope using the morphology-based key (Azari-Hamidian and Harbach 2009).
A sampling of larval mosquitoes at each station was performed in artificial, lightened, light-shaded, natural, permanent, and temporary habitats, and running, smooth, stagnant, turbid, vegetated, and non-vegetated water types of mosquito breeding places. The dipping technique was used to collect the mosquito larvae. Larval sampling took place equally in all areas every 15 days for 6 months from May to October 2018. In the laboratory, the larval specimens were mounted on the microscope slides with special needles in lactophenol and identified after a week using the morphology-based key (Azari-Hamidian and Harbach 2009).

\section{Statistical analysis}

The frequency trends of larval and adult mosquito species and the environment and water temperatures and environment humidity were estimated by Microsoft Excel 2013 during May to October. The frequency trend lines of larval and adult mosquito species with the environment and water temperatures and environment humidity were drawn by clicking on graph line distribution and selecting the 'add trend-line' option in Microsoft Excel (Zahirnia et al. $2019 b)$. The equations and R-squared values of trend lines of larval and adult mosquito species with environment and water temperatures and environment humidity were also calculated by Microsoft Excel (Zahirnia et al. 2019a).

IBM SPSS statistics data editor version 24 was used for inferential statistical analysis. One-sample KolmogorovSmirnov test was used to check the normality of the data distribution. After checking to make sure that the distribution of data was normal, an analysis of variance (ANOVA) and post hoc tests (Tukey) were used to compare the frequency of mosquitoes between larval habitats and water types of their breeding places, and adult mosquito monthly and locality distribution in Sanandaj County. Significant level was considered $P<0.05$.

\section{RESULTS AND DISCUSSION}

Figure 1 and Table 1 show the frequency of mosquito larvae and larval mosquito species, respectively, among habitats and water types of their breeding places in Sanandaj County from May to October 2018. Table 2 shows the frequency of mosquito species in numbers in rural and urban areas. Table 3 shows the monthly distribution of mosquitoes in numbers. Figures 2 and 3 also show the frequency of mosquitoes and mosquito species, respectively, in percent in rural and urban areas. Figure 4 shows the frequency of mosquito species in percent. Figures 5 and 6 show the monthly frequency and trends of larval and adult mosquito species and the environment and water temperatures, and environment humidity, respectively, in percent. Table 4 shows the frequency of adult mosquitoes in their resting places. Table 5 shows a one-way ANOVA analysis between the frequency of mosquitoes in larval habitats and water types of their breeding places, mosquito localities and life stages, monthly mosquito distribution, and adult resting places in Sanandaj County. 
Table 1. Distribution of larval mosquito species (\%) among habitats and water types of their breeding places in Sanandaj County from May to October 2018

\begin{tabular}{|c|c|c|c|c|c|c|c|c|c|c|c|c|}
\hline \multirow{2}{*}{$\begin{array}{c}\text { Larval mosquito } \\
\text { species }\end{array}$} & \multicolumn{6}{|c|}{ Habitats } & \multicolumn{6}{|c|}{ Water types } \\
\hline & Artificial & Lightened & Light-shaded & Natural & Permanent & Temporary & Running & Smooth & Stagnant & Turbid & Vegetated & Non-vegetated \\
\hline An. maculipennis s.l & 0 & 0.08 & 0.19 & 0.31 & 0.19 & 0.08 & 0.08 & 0.31 & 0.19 & 0.00 & 0.08 & 0.19 \\
\hline An. superpictus s.l & 0 & 0.11 & 0.44 & 0.56 & 0.44 & 0.11 & 0 & 0.56 & 0.56 & 0.00 & 0.22 & 0.33 \\
\hline Cs. longiareolata & 7.5 & 12.3 & 12.3 & 17.1 & 19.6 & 5.0 & 1.2 & 23.4 & 23.4 & 1.2 & 14.6 & 10.0 \\
\hline Cs. subochrea & 0.14 & 0.19 & 0.08 & 0.14 & 0.08 & 0.19 & 0.06 & 0.28 & 0.22 & 0 & 0.06 & 0.22 \\
\hline Cx. hortensis & 0 & 0 & 4.4 & 4.4 & 2.2 & 2.2 & 0 & 4.4 & 4.4 & 0 & 2.2 & 2.2 \\
\hline Cx. mimeticus & 0.08 & 0.47 & 0.19 & 0.58 & 0.58 & 0.08 & 0.36 & 0.58 & 0.31 & 0.08 & 0.58 & 0.08 \\
\hline Cx. modestus & 0.14 & 0.19 & 0.14 & 0.19 & 0.22 & 0.11 & 0 & 0.28 & 0.33 & 0.06 & 0.17 & 0.17 \\
\hline Cx. pipiens & 0.19 & 0.83 & 0.36 & 1.0 & 1.0 & 0.17 & 0 & 0.72 & 1.2 & 0.47 & 0.78 & 0.42 \\
\hline$C x$. theileri & 0.36 & 0.36 & 0.61 & 0.61 & 0.61 & 0.36 & 0.14 & 0.83 & 0.83 & 0.14 & 0.50 & 0.47 \\
\hline Total (mean) & 8.4 & 14.6 & 18.8 & 24.9 & 25.0 & 8.3 & 1.9 & 31.4 & 31.4 & 2.0 & 19.2 & 14.1 \\
\hline
\end{tabular}

Table 2. Frequency of larval and adult mosquito species (Numbers) in rural and urban areas in Sanandaj County from May to October 2018

\begin{tabular}{|c|c|c|c|c|c|c|c|c|c|c|c|c|c|c|c|c|c|c|c|c|c|c|c|}
\hline \multirow{3}{*}{$\begin{array}{c}\text { Area } \\
\text { Species } \\
\end{array}$} & \multicolumn{10}{|c|}{ Rural } & \multicolumn{10}{|c|}{ Urban } & \multirow{2}{*}{\multicolumn{3}{|c|}{ Overall }} \\
\hline & \multicolumn{2}{|c|}{ Kani-Moshkan } & \multicolumn{2}{|c|}{ Naran } & \multicolumn{2}{|c|}{ Salavat-Abad } & \multicolumn{2}{|c|}{ Turivar } & \multicolumn{2}{|c|}{ Total } & \multicolumn{2}{|c|}{ Abidar } & \multicolumn{2}{|c|}{ Baba-Riz } & \multicolumn{2}{|c|}{ Doveyseh } & \multicolumn{2}{|c|}{ Gerizeh } & \multicolumn{2}{|c|}{ Total } & & & \\
\hline & $\mathbf{L}$ & $\mathbf{A}$ & $\mathbf{L}$ & $\mathbf{A}$ & $\mathbf{L}$ & $\mathbf{A}$ & $\mathbf{L}$ & $\mathbf{A}$ & $\mathbf{L}$ & $\mathbf{A}$ & $\mathbf{L}$ & $\mathbf{A}$ & $\mathbf{L}$ & $\mathbf{A}$ & $\mathbf{L}$ & $\mathbf{A}$ & $\mathbf{L}$ & $\mathbf{A}$ & $\mathbf{L}$ & $\mathbf{A}$ & $\mathbf{L}$ & $\mathbf{A}$ & Total \\
\hline An. maculipennis s.1 & 0 & 0 & 0 & 0 & 0 & 0 & 0 & 0 & 0 & 0 & 0 & 0 & 11 & 0 & 0 & 0 & 0 & 0 & 11 & 0 & 11 & 0 & 11 \\
\hline An. superpictus s.l & 0 & 0 & 0 & 0 & 0 & 0 & 0 & 0 & 0 & 0 & 0 & 0 & 20 & 5 & 0 & 0 & 0 & 0 & 20 & 5 & 20 & 5 & 25 \\
\hline Cs. longiareolata & 41 & 33 & 185 & 51 & 90 & 32 & 364 & 42 & 680 & 158 & 65 & 30 & 77 & 24 & 36 & 31 & 28 & 17 & 206 & 102 & 886 & 260 & 1146 \\
\hline Cs. subochrea & 10 & 0 & 0 & 0 & 0 & 0 & 0 & 0 & 10 & 0 & 0 & 0 & 0 & 0 & 0 & 0 & 0 & 0 & 0 & 0 & 10 & 0 & 10 \\
\hline CX. hortensis & 21 & 0 & 36 & 1 & 0 & 0 & 63 & 0 & 120 & 1 & 0 & 0 & 14 & 8 & 26 & 0 & 0 & 0 & 40 & 8 & 160 & 9 & 169 \\
\hline Cx. mimeticus & 0 & 0 & 3 & 0 & 0 & 0 & 12 & 0 & 15 & 0 & 0 & 0 & 9 & 0 & 0 & 12 & 0 & 0 & 9 & 12 & 24 & 12 & 36 \\
\hline Cx. modestus & 0 & 0 & 0 & 0 & 0 & 0 & 12 & 0 & 12 & 0 & 0 & 0 & 0 & 0 & 0 & 0 & 0 & 0 & 0 & 0 & 12 & 0 & 12 \\
\hline Cx. pipiens & 0 & 0 & 16 & 20 & 0 & 0 & 16 & 0 & 32 & 20 & 0 & 0 & 10 & 21 & 1 & 0 & 0 & 0 & 11 & 21 & 43 & 41 & 84 \\
\hline Cx. theileri & 0 & 0 & 12 & 5 & 0 & 0 & 0 & 0 & 12 & 5 & 0 & 0 & 15 & 5 & 8 & 5 & 0 & 0 & 23 & 10 & 35 & 15 & 50 \\
\hline Total & 72 & 33 & 252 & 77 & 90 & 32 & 467 & 42 & 881 & 184 & 65 & 30 & 156 & 63 & 71 & 48 & 28 & 17 & 320 & 158 & 1201 & 342 & 1543 \\
\hline
\end{tabular}

L: Larva and A: Adult.

Table 3. Monthly distribution of mosquito species (Numbers) in Sanandaj County during May to October 2018

\begin{tabular}{|c|c|c|c|c|c|c|c|c|c|c|c|c|c|c|c|c|c|c|c|}
\hline \multirow{2}{*}{ Species } & \multicolumn{3}{|c|}{ May } & \multicolumn{3}{|c|}{ June } & \multicolumn{3}{|c|}{ July } & \multicolumn{3}{|c|}{ August } & \multicolumn{3}{|c|}{ September } & \multicolumn{3}{|c|}{ October } & \multirow{2}{*}{ Total } \\
\hline & Larva & Adult & Total & Larva & Adult & Total & Larva & Adult & Total & Larva & Adult & Total & Larva & Adult & Total & Larva & Adult & Total & \\
\hline An. maculipennis s.l & 0 & 0 & 0 & 0 & 0 & 0 & 0 & 0 & 0 & 12 & 0 & 12 & 0 & 0 & 0 & 0 & 0 & 0 & 12 \\
\hline An. superpictus s.l & 0 & 0 & 0 & 0 & 0 & 0 & 0 & 0 & 0 & 20 & 0 & 20 & 0 & 5 & 5 & 0 & 0 & 0 & 25 \\
\hline Cs. longiareolata & 16 & 0 & 16 & 123 & 40 & 163 & 411 & 62 & 473 & 158 & 40 & 198 & 120 & 84 & 204 & 57 & 34 & 91 & 1145 \\
\hline Cs. subochrea & 0 & 0 & 0 & 0 & 0 & 0 & 0 & 0 & 0 & 10 & 0 & 10 & 0 & 0 & 0 & 0 & 0 & 0 & 10 \\
\hline Cx. hortensis & 0 & 0 & 0 & 30 & 0 & 30 & 71 & 0 & 71 & 17 & 0 & 17 & 34 & 6 & 40 & 8 & 3 & 11 & 169 \\
\hline Cx. mimeticus & 0 & 0 & 0 & 4 & 0 & 4 & 8 & 0 & 8 & 9 & 12 & 21 & 3 & 0 & 3 & 0 & 0 & 0 & 36 \\
\hline Cx. modestus & 0 & 0 & 0 & 0 & 0 & 0 & 12 & 0 & 12 & 0 & 0 & 0 & 0 & 0 & 0 & 0 & 0 & 0 & 12 \\
\hline$C x$.pipiens & 4 & 8 & 12 & 13 & 0 & 13 & 16 & 10 & 26 & 6 & 11 & 17 & 4 & 12 & 16 & 0 & 0 & 0 & 84 \\
\hline Cx. theileri & 0 & 0 & 0 & 10 & 0 & 10 & 2 & 7 & 9 & 13 & 3 & 16 & 10 & 5 & 15 & 0 & 0 & 0 & 50 \\
\hline Total & 20 & 8 & 28 & 180 & 40 & 220 & 520 & 79 & 599 & 245 & 66 & 311 & 171 & 112 & 283 & 65 & 37 & 102 & 1543 \\
\hline
\end{tabular}




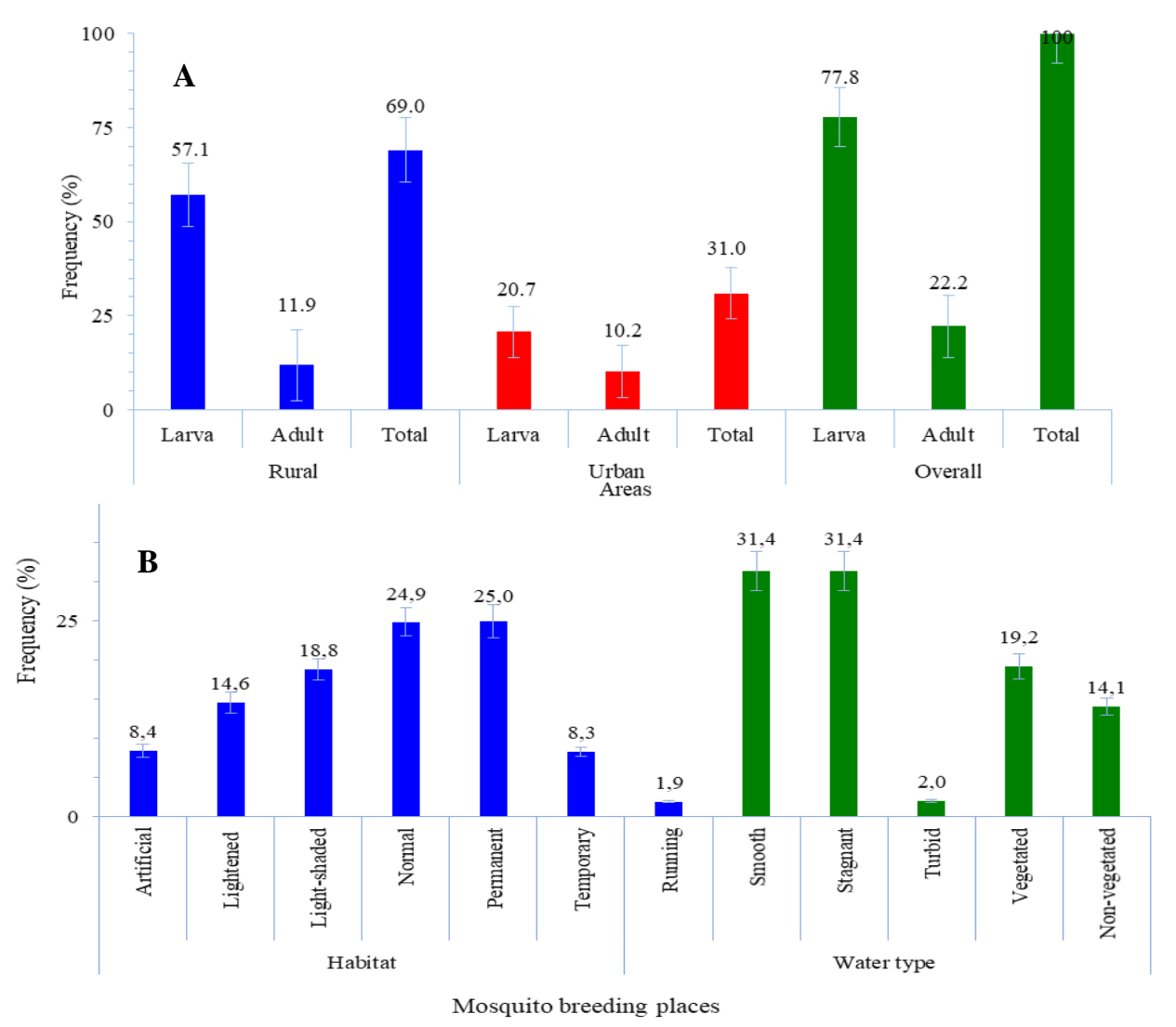

Figure 1. Frequency of mosquito larvae (\%) among habitats and water types of their breeding places in Sanandaj County from May to October 2018. A. Frequency of mosquito larvae in rural and urban areas, B. Frequency of mosquito larvae in habitats and water types of their breeding places
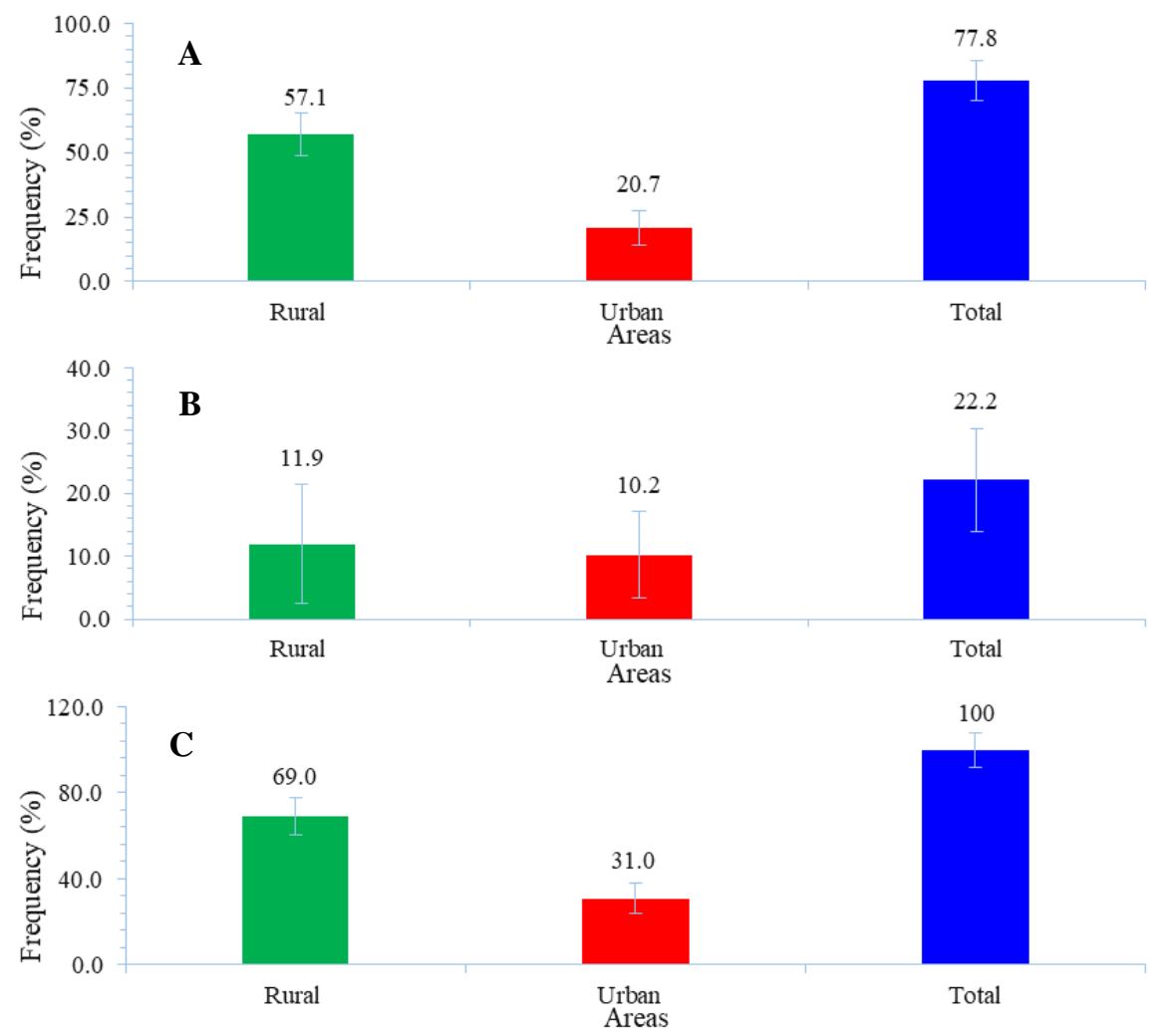

Figure 2. Frequency of mosquitoes (\%) in rural and urban areas in Sanandaj County from May to October 2018. A. Frequency of mosquito larvae in rural and urban areas, B. Frequency of adult mosquitoes in rural and urban areas, C. Total frequency of mosquitoes in rural and urban areas 


\section{Frequency of mosquito larvae in habitats and water} types of their breeding places

The frequency of mosquito larvae in habitats of their breeding places was temporary $(8.3 \%)$, artificial $(8.4 \%)$, lightened $(14.6 \%)$, light-shaded $(18.8 \%)$, natural $(24.9 \%)$, and permanent $(25.0 \%)$ in order. The frequency of mosquito larvae among water types of their breeding places was also running $(1.9 \%)$, turbid $(2.0 \%)$, non-vegetated $(14.1 \%)$, vegetated $(19.2 \%)$, smooth $(31.4 \%)$, and stagnant $(31.4 \%)$ in order. The most attractive mosquito habitat was light-shaded $(18.8 \%)$, natural $(24.9 \%)$, and permanent (25.0\%) with vegetated (19.2\%), smooth (31.4\%), and stagnant $(31.4 \%)$ water types of their breeding places in order (Table 1, Figure 1).

The frequency of larval mosquito species were Culiseta subochrea (0.83\%), Anopheles maculipennis s.1. (0.86\%), Cx. modestus (1.0\%), An. superpictus s.1. (1.7\%), Cx. mimeticus (2.0\%), Cx. theileri $(2.9 \%), C x$. pipiens $(3.6 \%)$, Cx. hortensis (13.3\%), and Cs. longiareolata (73.8\%) in order in the habitats and water types of mosquito breeding places. One-way ANOVA didn't reveal a significant difference between the habitats $(\mathrm{F}=0.335$, df $=5, P=$ 0.889 ), and water types of mosquito breeding places $(\mathrm{F}=$ 0.796 , df $=5, P=0.558$ ) (Table 5).

\section{Frequency of mosquitoes in rural and urban localities}

The frequency of mosquito larvae in selected rural sites was higher than in urban areas (Table 2, Figure 2A). However, the frequency of adult mosquitoes in rural and urban areas was close to each other (Figure 2B). One-way ANOVA didn't reveal a significant difference between the frequency of mosquito life stages in rural and urban areas ( $\mathrm{F}=0.926, \mathrm{df}=1, P=0.350$ ) (Table 5). In terms of species composition An. maculipennis s.l. and An. superpictus s.l. were not observed in rural areas. Conversely, Cs. subochrea and Cx. modestus was not observed in urban areas (Figure 3). In total, in this study 9 mosquito species, including Cs. subochrea (0.65\%), An. maculipennis s.l. (0.78\%), Cx. modestus (0.78\%), An. superpictus s.l. (1.6\%), Cx. mimeticus (2.3\%), Cx. theileri (3.2\%), Cx. pipiens (5.4\%), Cx. hortensis (11.0\%), and Cs. longiareolata $(74.2 \%)$ in order were collected. The most abundant mosquito species were Cs. longiareolata in rural and urban areas (Figure 4C). One-way ANOVA didn't reveal a significant difference between the frequency of mosquitoes in rural and urban areas $(\mathrm{F}=0.0001, \mathrm{df}=1, P$ $=0.999)($ Table 5).

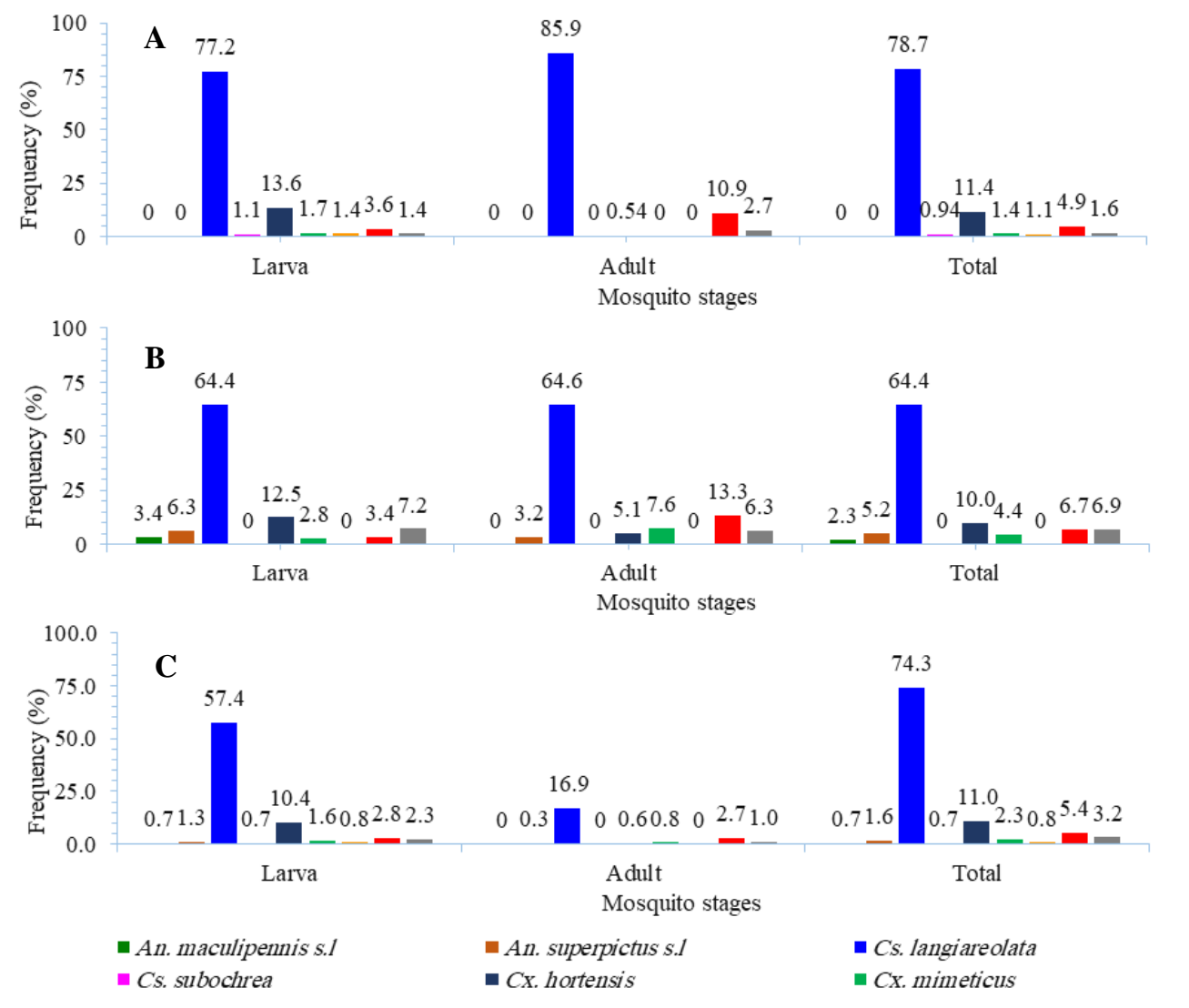

Figure 3. Frequency of mosquito species (\%) in Sanandaj County from May to October 2018. A. Frequency of mosquito species in rural area, B. Frequency of mosquito species in urban area, C. Total frequency of mosquito species 
Table 4. Frequency of adult mosquito species in their resting places in Sanandaj County from May to October 2018

\begin{tabular}{|c|c|c|c|c|c|c|c|}
\hline Mosquito species & Indoors & Stable & Toilet & Warehouse & Total catch & Others & Total \\
\hline \multicolumn{8}{|l|}{ Numbers } \\
\hline An. superpictus s.l & 0 & 0 & 0 & 0 & 3 & 0 & 3 \\
\hline Cs. longiareolata & 2 & 60 & 8 & 38 & 170 & 50 & 328 \\
\hline CX. hortensis & 0 & 1 & 0 & 0 & 17 & 0 & 18 \\
\hline Cx. mimeticus & 0 & 0 & 0 & 0 & 8 & 0 & 8 \\
\hline Cx. pipiens & 0 & 12 & 0 & 2 & 10 & 6 & 30 \\
\hline Cx. theileri & 0 & 5 & 0 & 0 & 0 & 0 & 5 \\
\hline Total & 2 & 78 & 8 & 40 & 208 & 56 & 392 \\
\hline \multicolumn{8}{|l|}{ Percentage } \\
\hline An. superpictus s.l & 0 & 0 & 0 & 0 & 0.77 & 0 & 0.77 \\
\hline Cs. longiareolata & 0.51 & 15.3 & 2.0 & 9.7 & 43.4 & 12.8 & 83.7 \\
\hline Cx. hortensis & 0 & 0.26 & 0 & 0 & 4.3 & 0 & 4.6 \\
\hline Cx. mimeticus & 0 & 0 & 0 & 0 & 2.0 & 0 & 2.0 \\
\hline Cx. pipiens & 0 & 3.1 & 0 & 0.5 & 2.6 & 1.5 & 7.7 \\
\hline Cx. theileri & 0 & 1.3 & 0 & 0 & 0 & 0 & 1.3 \\
\hline Total & 0.51 & 19.9 & 2.0 & 10.2 & 53.1 & 14.3 & 100 \\
\hline
\end{tabular}
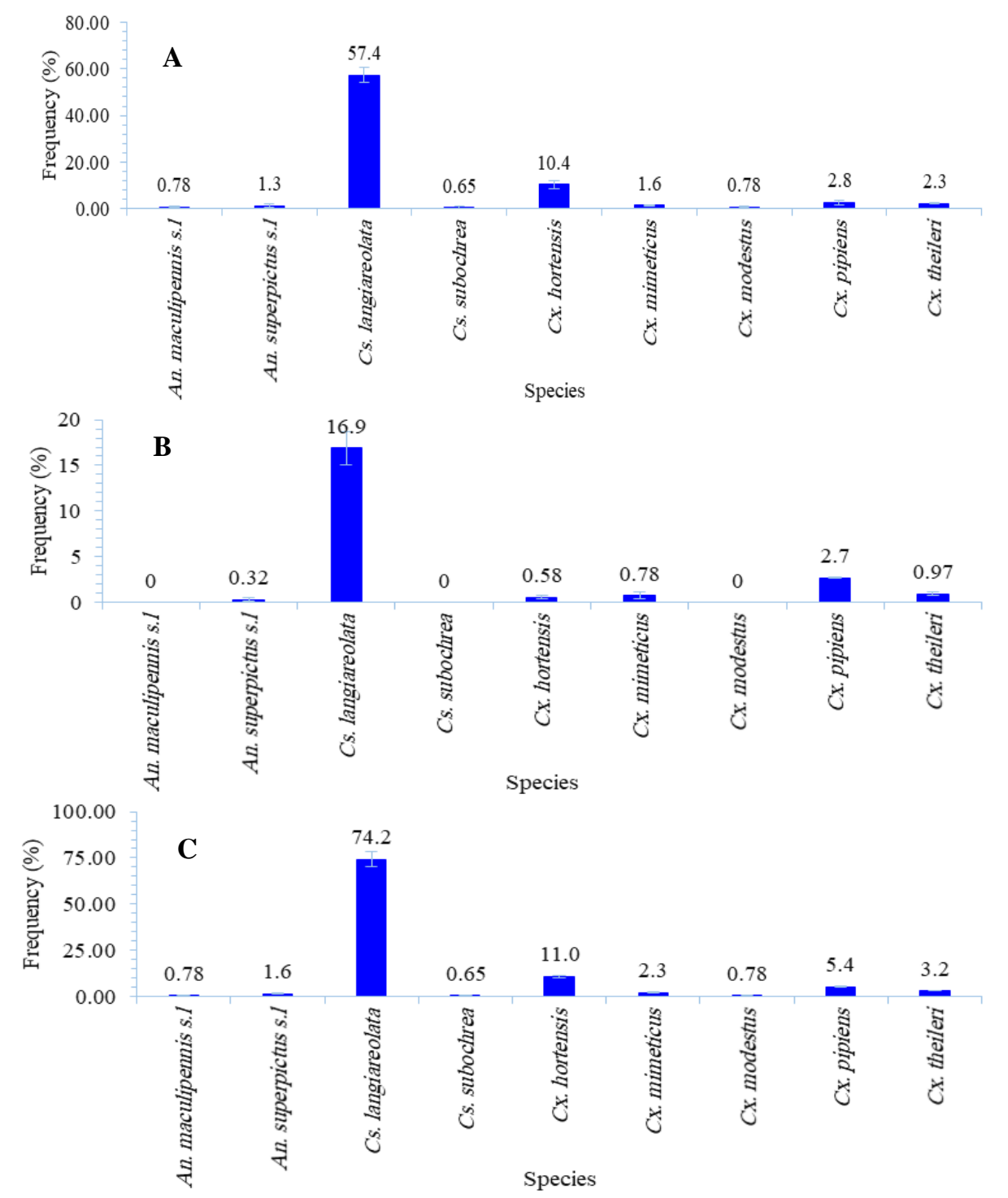

Figure 4. Frequency of mosquito species (\%) in Sanandaj County from May to October 2018. A. Frequency of larval mosquito species, B. Frequency of adult mosquito species, C. Total frequency of mosquito species 
Table 5. One-way ANOVA analysis between the frequency of mosquitoes (\%) in larval habitats and water types of their breeding places, mosquito localities and life stages, mosquito monthly distribution, and adult resting places in Sanandaj County

\begin{tabular}{|c|c|c|c|}
\hline Larval habitats & Mean & $\begin{array}{c}\text { Std. } \\
\text { deviation }\end{array}$ & $\begin{array}{c}\text { Std. } \\
\text { error }\end{array}$ \\
\hline Artificial & 0.93 & 2.5 & 0.82 \\
\hline Lightened & 1.6 & 4.0 & 1.3 \\
\hline Light-shaded & 2.1 & 4.1 & 1.4 \\
\hline Natural & 2.8 & 5.5 & 1.8 \\
\hline Permanent & 2.8 & 6.3 & 2.1 \\
\hline Temporary & 0.92 & 1.7 & 0.56 \\
\hline \multicolumn{4}{|l|}{ Water types } \\
\hline Running & 0.20 & 0.39 & 0.13 \\
\hline Smooth & 3.5 & 7.6 & 2.5 \\
\hline Stagnant & 3.5 & 7.6 & 2.5 \\
\hline Turbid & 0.22 & 0.40 & 0.13 \\
\hline Vegetated & 2.1 & 4.7 & 1.6 \\
\hline Non-vegetated & 1.6 & 3.2 & 1.1 \\
\hline \multicolumn{4}{|l|}{ Locality } \\
\hline Rural & 11.1 & 25.6 & 8.5 \\
\hline Urban & 11.1 & 20.3 & 6.8 \\
\hline \multicolumn{4}{|l|}{ Monthly distribution } \\
\hline May & 0.20 & 0.41 & 0.14 \\
\hline June & 1.6 & 3.4 & 1.1 \\
\hline July & 4.3 & 10.0 & 3.3 \\
\hline August & 2.2 & 4.0 & 1.3 \\
\hline September & 2.0 & 4.3 & 1.4 \\
\hline October & 0.73 & 2.0 & 0.65 \\
\hline \multicolumn{4}{|l|}{ Adult resting places } \\
\hline Indoors & 0.09 & 0.21 & 0.09 \\
\hline Stable & 3.3 & 6.0 & 2.4 \\
\hline Toilet & 0.33 & 0.82 & 0.33 \\
\hline Warehouse & 1.7 & 3.9 & 1.6 \\
\hline Total catch & 8.8 & 17.0 & 6.9 \\
\hline Others & 2.4 & 5.1 & 2.1 \\
\hline \multicolumn{4}{|l|}{ Mosquito life stage } \\
\hline Larva & 8.7 & 18.5 & 6.2 \\
\hline Adult & 2.5 & 5.5 & 1.8 \\
\hline ANOVA analysis & $\begin{array}{l}\text { Sum of } \\
\text { squares } \\
\text { (df) }\end{array}$ & $\begin{array}{l}\text { Mean } \\
\text { square }\end{array}$ & $\begin{array}{c}\text { F }(P- \\
\text { value })\end{array}$ \\
\hline $\begin{array}{l}\text { Between mosquito } \\
\text { larval habitats }\end{array}$ & $31.4(5)$ & 6.3 & $\begin{array}{c}0.335 \\
(0.889)\end{array}$ \\
\hline $\begin{array}{l}\text { Between water types } \\
\text { of mosquito breeding } \\
\text { places }\end{array}$ & $98.2(5)$ & 19.6 & $\begin{array}{c}0.796 \\
(0.558)\end{array}$ \\
\hline $\begin{array}{l}\text { Between mosquito } \\
\text { localities }\end{array}$ & $0.001(1)$ & 0.001 & $\begin{array}{l}0.0001 \\
(0.999)\end{array}$ \\
\hline $\begin{array}{l}\text { Between mosquito } \\
\text { monthly distribution }\end{array}$ & $92.6(5)$ & 18.5 & $\begin{array}{c}0.742 \\
(0.596)\end{array}$ \\
\hline $\begin{array}{l}\text { Between adult resting } \\
\text { places }\end{array}$ & $309.9(5)$ & 62.0 & $\begin{array}{l}1.013 \\
(0.427)\end{array}$ \\
\hline $\begin{array}{l}\text { Between mosquito life } \\
\text { stages }\end{array}$ & $172.7(1)$ & 172.7 & $\begin{array}{c}0.926 \\
(0.350)\end{array}$ \\
\hline
\end{tabular}

\section{Monthly distribution of mosquitoes}

The population density of larval and adult mosquito species gradually increased with an increasing average temperature of water and environment on an adequate relative humidity from May to July or August. Conversely, the population density of larval and adult mosquito species gradually decreased with decreasing average water temperature and environment on an adequate relative humidity from July or August to October (Table 3, Figure 5). The frequency trends of larval and adult mosquito species with an adequate temperature of water and environment and relative humidity remain constant from May to October (Figure 6). One-way ANOVA didn't reveal a significant difference between the mosquitoes monthly distribution $(\mathrm{F}=0.742, \mathrm{df}=5, P=0.596)$ (Table $5)$.

\section{Frequency of adult mosquitoes in their resting places}

The frequency of adult mosquitoes in their resting areas was indoors $(0.51 \%)$, toilet $(2.0 \%)$, warehouse $(10.2 \%)$, others (14.3\%), and stable (19.9\%) in order (Table 4). Oneway ANOVA didn't reveal a significant difference between the frequency of adult mosquitoes in their resting places ( $\mathrm{F}$ $=1.013, \mathrm{df}=5, P=0.427)($ Table 5).

\section{Discussion}

Among humans considered global public health threats such as ticks, scabies, pediculosis, myiasis, leishmaniosis, and cockroaches (Nasirian et al. 2006; Nasirian 2017a; Nasirian 2017b; Davari et al. 2018; Nasirian 2019a; Nasirian 2019b; Nasirian and Salehzadeh 2019a; Nasirian and Salehzadeh 2019b; Nasirian 2020; Salehzadeh et al. 2020; Kassiri and Nasirian 2021; Nasirian and Saghafipour 2021; Nasirian and Zahirnia 2021; Tavakoli et al. 2021; Zahirnia et al. 2021), mosquitoes are the most significant arthropods of medical importance due to their burden of transmitting pathogens and parasites to humans (Fakour et al. 2017; Parhizgari et al. 2017; Wahid et al. 2017; Atkinson and Hewson 2018; Azari-Hamidian et al. 2019). In total, the results of this study indicate that 9 mosquito species, including An. maculipennis s.l., An. superpictus s.1., Cs. longiareolata, Cs. subochrea, Cx. hortensis, $C x$. mimeticus, $C x$. modestus, $C x$. pipiens, and $C x$. theileri inhabit the Sanandaj County (Figure 4C). Anopheles maculipennis s.l. and An. superpictus s.l. are vectors of malaria in Iran. Anopheles maculipennis s.l. and $C x$. pipiens are the vectors of setariasis, a worldwide disease that infects a wide range of ruminants in Italy (AzariHamidian et al. 2019). Cx. modestus and Cx. pipiens are vectors of West Nile fever in Europe. Cx. modestus, $C x$. pipiens and $C x$. theileri are vectors of avian malaria (bird malaria) in Spain. Cx. pipiens is the vector of avian malaria (bird malaria) in Austria, Japan, Madagascar, Portugal, Spain, and Turkey. Cx. pipiens is the vector of Rift Valley fever, Sindbis fever, and West Nile fever in Egypt, Sweden, and North America.

Recently West Nile fever virus was found in $C x$. pipiens in Guilan Province of Iran. Cx. theileri is also the vector of Rift Valley fever and dirofilariasis (dirofilariasis) in South Africa and Portugal, respectively (Ferraguti et al. 2013; Gholami-Ahangaran et al. 2014; Azari-Hamidian et al. 2019). Twelve mosquito species, including Aedes vexans, An. claviger, An. maculipennis (s.1.), An. superpictus, Cx. hortensis, Cx. mimeticus, Cx. perexiguus, $C x$. pipiens, $C x$. theileri, Culiseta longiareolata, Cs. subochrea, and Ochlerotatus caspius s.l. were recorded in 
this region (Kazemi et al. 2010; Banafshi et al. 2013). Ae. vexans, An. claviger, and $C x$. perexiguus, were not observed in the current study, probably due to species variation in seasonal mosquito distribution.

Because mosquitoes are considered threats to human health due to mosquito-borne diseases and long-lasting nuisance and itching of their bite positions, they can prevent native people and tourist activities (Lanciotti et al. 1999; Savage et al. 2007; Nasirian et al. 2014a; Nasirian et al. 2014b). Travel to tourism sites or migratory bird habitats like wetlands that possess natural tourism attractions with their unique mosquito biodiversity has been identified as risky places to transmit mosquito-borne diseases (Nasirian et al. 2013; Nasirian et al. 2015; Nasirian et al. 2016; Nasirian and Irvine 2017).

As Kurdistan Province, especially Sanandaj, the capital of Kurdistan Province in Iran, has a tourism destination because it is a wonderful place in the domains of mountainous areas with excellent weather and some popular tourist attractions, and there are many aquatic habitats in Sanandaj County. The frequency trends of larval and adult mosquito species with an adequate temperature of water and environment and relative humidity remain constant at least for 6 months of a year (e.g., during May to
October) (Figure 6). Therefore, it needs to be ready for timely mosquito control measures.

The most attractive mosquito breeding places were light-shaded, natural, and permanent habitats with vegetation, smooth, and stagnant type waters of mosquito breeding places (Table 1, Figure 1). That must be extra focus on them to control mosquito larvae. Because oneway ANOVA didn't reveal a significant difference between the frequency of mosquito in habitats $(\mathrm{F}=0.335, \mathrm{df}=5, P$ $=0.889)$, and water types of their breeding places $(\mathrm{F}=$ 0.796 , df $=5, P=0.558)$, rural and urban mosquito localities $(\mathrm{F}=0.0001$, $\mathrm{df}=1, P=0.999)$, mosquito monthly distribution $(\mathrm{F}=0.742$, $\mathrm{df}=5, P=0.596)$, and adult mosquito resting places $(\mathrm{F}=1.013, \mathrm{df}=5, P=0.427)$ (Table 5). We should also be focused on the other levels of mosquito control. In the face of anthropogenic climate change, the problem becomes even more challenging. The trends of increase and decrease year by year of vectorborne diseases support the theory of the role of climate change. Warming climates facilitate the range expansion of many taxa to habitats of higher latitudes and elevations (Nasirian and Salehzadeh 2019b).

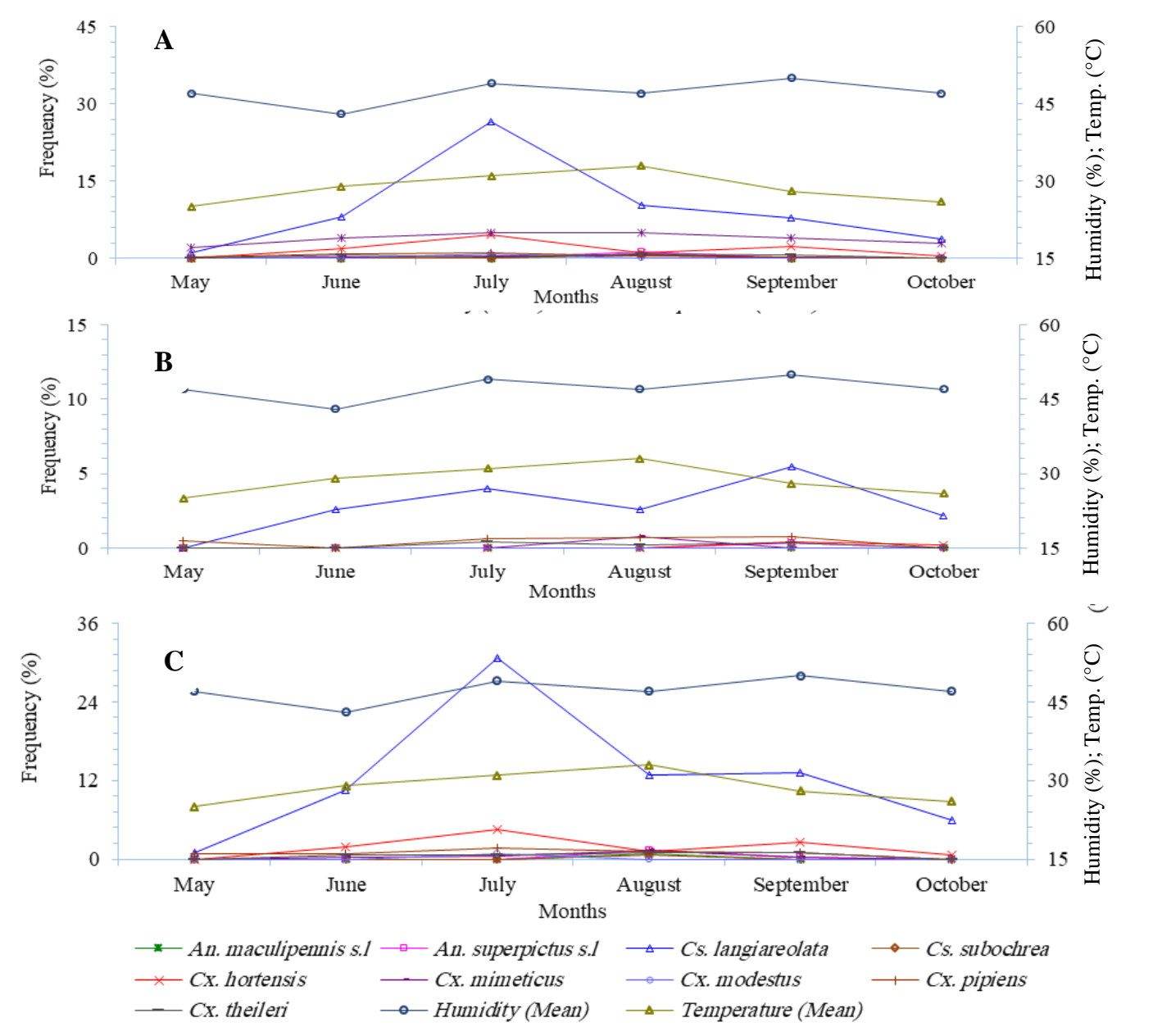

Figure 5. Frequency of larval and adult mosquito species (\%) along with environment and water temperature, and environment humidity in Sanandaj County during May to October 2018. A. Frequency of larval mosquito species, B. Frequency of adult mosquito species, C. Total frequency of mosquito species 

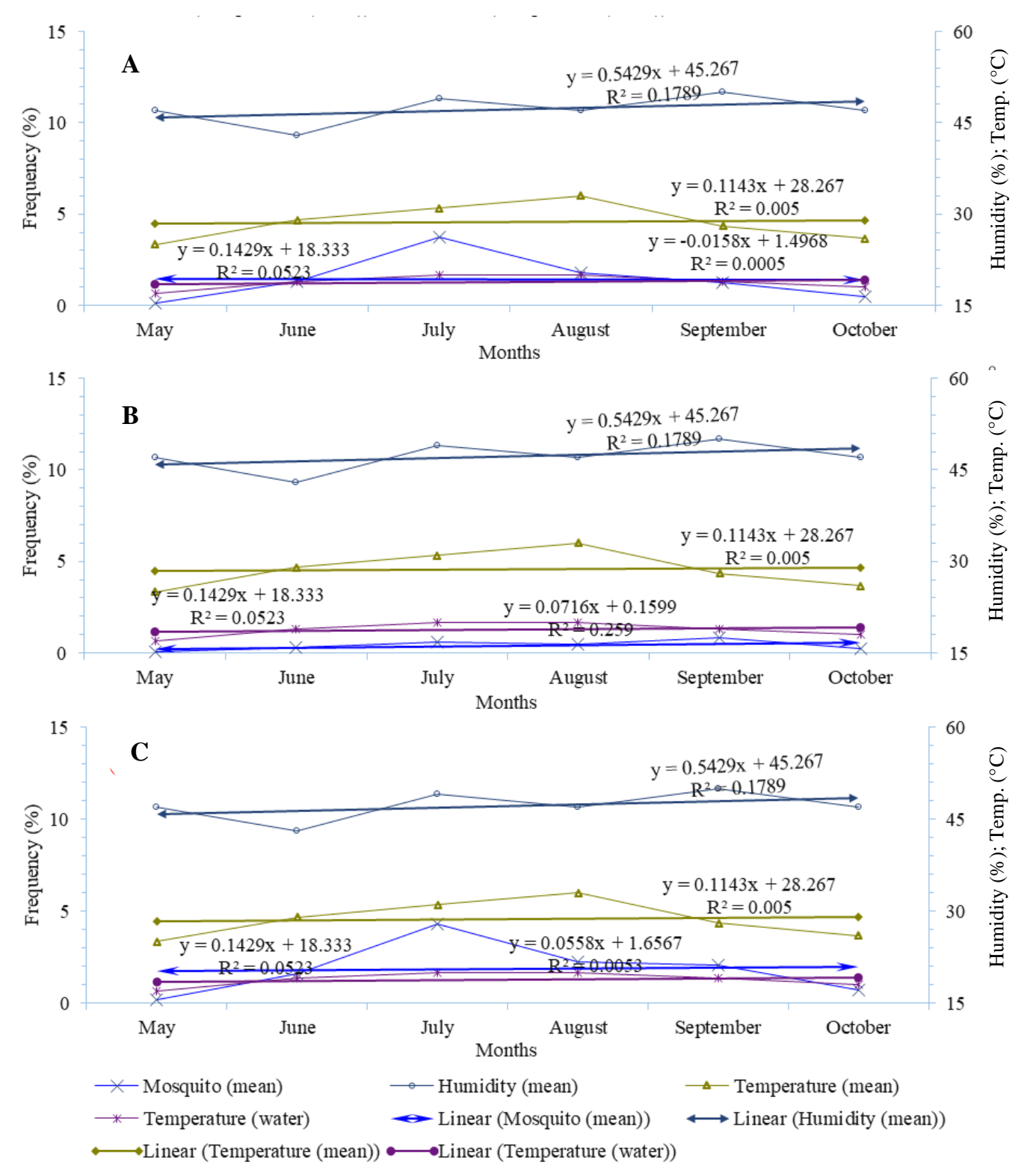

Figure 6. Frequency trends of larval and adult mosquito species along with environment and water temperature, and environment humidity in Sanandaj County during May to October 2018. A. Trend of mosquito larvae, B. Trend of adult mosquitoes, C. Total trend of mosquitoes

To conclude, the results of the study indicated that $A n$. maculipennis s.l., An. superpictus s.l., Cs. longiareolata, Cs. subochrea, Cx. hortensis, Cx. mimeticus, Cx. modestus, $C x$. pipiens, and $C x$. theileri were found in Sanandaj County. The frequency trends of larval and adult mosquito species remain constant at least for 6 months of a year. It needs to be ready for timely mosquito control measures. The most attractive mosquito breeding places were lightshaded, natural, and permanent habitats with vegetation, smooth, and stagnant water types of mosquito breeding places. That must be extra focus on them to control mosquito larvae.

\section{ACKNOWLEDGEMENTS}

This study forms part of Bahaedin Salavati's thesis in Medical Entomology and Vector Control in the Department of Medical Entomology, School of Medicine, Hamadan University of Medical Sciences. Iran supported financially by the Research Deputy of Hamadan University of Medical Sciences, Iran (Grant No: 9705303223). The study was also approved by the ethics committee of the Research Deputy of Hamadan University of Medical Sciences (IR.UMSHA.REC.1397.341). The authors declare that no competing interests. 


\section{REFERENCES}

Atkinson B, Hewson R. 2018. Emerging arboviruses of clinical importance in Central Asia. J Gen Virol 99: 1172-1184. DOI: 10.1099/jgv.0.001125

Azari-Hamidian S, Harbach RE. 2009. Keys to the adult females and fourth-instar larvae of the mosquitoes of Iran (Diptera: Culicidae). Zootaxa 2078: 1-33. DOI: 10.5281/zenodo.187282

Azari-Hamidian S, Norouzi B, Harbach RE. 2019. A detailed review of the mosquitoes (Diptera: Culicidae) of Iran and their medical and veterinary importance. Acta Trop 194: 106-122. DOI: 10.1016/j.actatropica.2019.03.019

Banafshi O, Abai M, Ladonni H, Bakhshi H, Karami H, Azari-Hamidian S. 2013. The fauna and ecology of mosquito larvae (Diptera: Culicidae) in western Iran. Turk J Zool 37: 298-307. DOI: 10.3906/zoo-1206-12

Benelli G, Duggan MF. 2018. Management of arthropod vector datasocial and ecological dynamics facing the One Health perspective. Acta Trop 182: 80-91. DOI: 10.1016/j.actatropica.2018.02.015

Davari B, Kashani S, Nasirian H, Nazari M, Salehzadeh A. 2018. The efficacy of MaxForce and Avion gel baits containing fipronil, clothianidin and indoxacarb against the German cockroach (Blattella germanica). Entomol Res 48: 459-465. DOI: 10.1111/1748 5967.12282

Fakour S, Naserabadi S, Ahmadi E. 2017. The first positive serological study on Rift Valley fever in ruminants of Iran. J Vector Borne Dis 54: 348-352. DOI: 10.4103/0972-9062.225840

Ferraguti M, Martínez-de la PJ, Muñoz J, Roiz D, Ruiz S, Soriguer R, Figuerola J. 2013. Avian Plasmodium in Culex and Ochlerotatus mosquitoes from southern Spain: Effects of season and host-feeding source on parasite dynamics. Plos One 8 (6): e66237. DOI: 10.1371/journal.pone.0066237

Gholami-Ahangaran M, Zia-Jahromi N, Namjoo A. 2014. Molecular detection of avian pox virus from nodular skin and mucosal fibrinonecrotic lesions of Iranian backyard poultry. Trop Anim Health Prod 46: 349-353. DOI: 10.1007/s11250-013-0495-z

Kakeh-Khani A, Nazari M, Nasirian H. 2020. Insecticide resistance studies on German cockroach (Blattella germanica) strains to malathion, propoxur and lambdacyhalothrin. Chula Med J 64: 357 365. DOI: $10.14456 / \mathrm{clmj} .2020 .45$

Kassiri H, Nasirian H. 2021. New insights about human tick infestation features: A systematic review and meta-analysis. Environ Sci Pollut Res Intl 28: 17000-17028. DOI: 10.1007/s11356-021-13102-6

Kazemi SH, Karimian F, Davari B. 2010. Culicinae mosquitoes in Sanandaj county, Kurdistan province, western Iran. J Vector Borne Dis 47: 103-107.

Lanciotti R, Roehrig J, Deubel V, Smith J, Parker M, Steele K, Crise B, Volpe K, Crabtree M, Scherret J. 1999. Origin of the West Nile virus responsible for an outbreak of encephalitis in the northeastern United States. Science 286: 2333-2337. DOI: 10.1126/science.286.5448.2333

Marm-Kilpatrick A, Daszak P, Jones MJ, Marra PP, Kramer LD. 2006. Host heterogeneity dominates West Nile virus transmission. Proc Biol Sci 273: 2327-2333. DOI: 10.1098/rspb.2006.3575

Mostafavi E, Shahraki AH, Japoni-Nejad A, Esmaeili S, Darvish J, Sedaghat MM, Mohammadi A, Mohammadi Z, Mahmoudi A, Pourhossein B. 2017. A field study of plague and tularemia in rodents, Western Iran. Vector Borne Zoonotic Dis 17: 247-253. DOI: 10.1089/vbz.2016.2053

Nasirian H. 2017. Contamination of cockroaches (Insecta: Blattaria) to medically fungi: A systematic review and meta-analysis. J Mycol Med 27 (4): 427-448. DOI: 10.1016/j.mycmed.2017.04.012

Nasirian H. 2017. Infestation of cockroaches (Insecta: Blattaria) in the human dwelling environments: A systematic review and metaanalysis. Acta Trop 167: 86-98. DOI: 10.1016/j.actatropica.2016.12.019

Nasirian H. 2019a. Contamination of cockroaches (Insecta: Blattaria) by medically important bacteriae: A systematic review and metaanalysis. J Med Entomol 56: 1534-1554. DOI: 10.1093/jme/tjz095

Nasirian H. 2019b. Crimean-Congo hemorrhagic fever (CCHF) seroprevalence: A systematic review and meta-analysis. Acta Trop 196: 102-120. DOI: 10.1016/j.actatropica.2019.05.019

Nasirian H. 2020. New aspects about Crimean-Congo hemorrhagic fever (CCHF) cases and associated fatality trends: A global systematic review and meta-analysis. Comp Immunol Microbiol Infect Dis 69 : 101429 DOI: 10.1016/j.cimid.2020.101429
Nasirian H, Irvine K. 2017. Odonata larvae as a bioindicator of metal contamination in aquatic environments: Application to ecologically important wetlands in Iran. Environ Monit Assess 189: 436. DOI: 10.1007/s10661-017-6145-6

Nasirian H, Irvine K, Sadeghi S, Mahvi A, Nazmara S. 2016. Assessment of bed sediment metal contamination in the Shadegan and Hawr Al Azim wetlands, Iran. Environ Monit Assess 188: 1-15. DOI: 10.1007/s10661-016-5117-6

Nasirian H, Ladonni H, Shayeghi M, Vatandoost H, Rassi Y, Ershadi MY, Rafinejad J, Basseri H. 2006. Duration of fipronil WHO glass jar method toxicity against susceptible and feral German Cockroach strains. Pak J Biol Sci 9: 1955-1959. DOI: 10.3923/pjbs.2006.1955.1959

Nasirian H, Mahvi AH, Hosseini M, Vazirianzadeh B, Sadeghi SM, Nazmara S. 2013. Study on the heavy metal bio-concentrations of the Shadegan international wetland mosquitofish, Gambusia affinis, by inductively coupled plasma technique. J Environ Health Sci Eng 11 (1): 22 . DOI: $10.1186 / 2052-336 \mathrm{X}-11-22$

Nasirian H, Nazmara S, Mahvi AH, Hosseini M, Shiri L, Vazirianzadeh B. 2015. Assessment of some heavy metals in the Shadegan and Hawr Al Hawizea wetland waters from Iran. Indian J Sci Technol 8: 1-9. DOI: $10.17485 / \mathrm{ijst} / 2015 / \mathrm{v} 8 \mathrm{i} 33 / 53997$

Nasirian H, Sadeghi SMT, Vazirianzadeh B, Moosa-Kazemi SH. 2014. New record of Aedes vittatus and Culiseta subochrea (Diptera: Culicidae) and their distribution from Shadegan Wetland, South Western Iran. J Entomol Zool Stud 2 (5): 271-275.

Nasirian H, Saghafipour A. 2021. Efficacy of several insecticide formulations against Periplaneta americana (L.) (Blattaria: Blattidae) in sewers. Bangladesh $\mathrm{J}$ Med Sci 20: 569-585. DOI: 10.3329/bjms.v20i3.52800

Nasirian H, Salehzadeh A. 2019. Control of cockroaches (Blattaria) in sewers: A practical approach systematic review. J Med Entomol 56 (1): 181-191. DOI: $10.1093 /$ jme/tjy205

Nasirian H, Salehzadeh A. 2019. Effect of seasonality on the population density of wetland aquatic insects: a case study of the Hawr Al Azim and Shadegan wetlands, Iran. Vet World 12: 584-592. DOI: 10.14202/vetworld.2019.584-592

Nasirian H, Vazirianzadeh B, Taghi SSM, Nazmara S. 2014. Culiseta subochrea as a bioindicator of metal contamination in Shadegan International Wetland, Iran (Diptera: Culicidae). J Insect Sci 14: 258. DOI: $10.1093 /$ jisesa/ieu 120

Nasirian H, Zahirnia A. 2021. Detailed infestation spectrums about biological stages of hard ticks (Acari: Ixodida: Ixodidae) in humans: A systematic review and meta-analysis. Acta Parasitol 66: 770-796. DOI: 10.1007/s11686-021-00362-y

Parhizgari N, Gouya MM, Mostafavi E. 2017. Emerging and re-emerging infectious diseases in Iran. Iran J Microbiol 9: 122-142.

Salehzadeh A, Darvish Z, Davari B, Nasirian H. 2020. The efficacy of baits containing abamectin, dinotefuran, imidacloprid and pyriproxyfen+ abamectin against Blattella germanica (L.) (Blattaria: Blattellidae), the German cockroach. Afr Entomol 28: 225-237. DOI: 10.4001/003.028.0225

Savage HM, Aggarwal D, Apperson CS, Katholi CR, Gordon E, Hassan HK, Anderson M, Charnetzky D, McMillen L, Unnasch EA, Unnasch TR. 2007. Host choice and West Nile virus infection rates in bloodfed mosquitoes, including members of the Culex pipiens complex, from Memphis and Shelby county, Tennessee, 2002-2003. Vector Borne Zoonotic Dis 7: 365-386. DOI: 10.1089/vbz.2006.0602

Suesdek L. 2019. Microevolution of medically important mosquitoes-a review. Acta Trop 191: 162-171. DOI: 10.1016/j.actatropica.2018.12.013

Tavakoli MM, Davari B, Nasirian H, Salehzadeh A, Moradkhani S, Zahirnia AH. 2021. Investigation of insecticidal properties of Rosmarinus officinalis and Lavandula angustifolia essential oils against German cockroach in laboratory. J Kashan Univ Med Sci 25 (3): 994-1002.

Wahid B, Ali A, Rafique S, Idrees M. 2017. Global expansion of chikungunya virus: Mapping the 64-year history. Intl J Infect Dis 58: 69-76. DOI: 10.1016/j.ijid.2017.03.006

Zahirnia A, Aminpoor MA, Nasirian H. 2021. The impact and trend of factors affecting the prevalence of head lice (Pediculus capitis) infestation in primary school students. Chula Med J 65 (4): 359-368. DOI: $10.14456 / \mathrm{clmj} .2021 .47$

Zahirnia A, Boroomand M, Nasirian H, Salehzadeh A, Soleimani-Asl S. 2019. Comparing cytotoxicity of propoxur and Nepeta crispa (Lamiales: Lamiaceae) essential oil against invertebrate (Sf9) and 
vertebrate (L929) cell lines. Vet World 12: 1698-1706. DOI: 10.14202/vetworld.2019.1698-1706

Zahirnia A, Boroomand M, Nasirian H, Soleimani-Asl S, Salehzadeh A, Dastan D. 2019. The cytotoxicity of malathion and essential oil of
Nepeta crispa (lamiales: lamiaceae) against vertebrate and invertebrate cell lines. Pan Afr Med J 33: 285. DOI: 10.11604/pamj.2019.33.285.18776 